\title{
Mean values, normal limits and sex differences of anthropometry of young adults in a University Community in Nigeria
}

\author{
Oluwadare Ogunlade*, Olusoji Adeola Adalumo \\ Department of Physiological Sciences, Obafemi Awolowo University, Ile-Ife, Nigeria \\ Email address: \\ oogunlade@oauife.edu.ng (O. Ogunlade),infosoj@gmail.com (O. A. Adalumo)
}

\section{To cite this article:}

Oluwadare Ogunlade, Olusoji Adeola Adalumo. Mean Values, Normal Limits and Sex Differences of Anthropometry of Young Adults in a University Community in Nigeria. American Journal of Clinical and Experimental Medicine. Vol. 3, No. 1, 2015, pp. 44-47. doi: 10.11648/j.ajcem.20150301.16

\begin{abstract}
This study assessed the weight, height, body mass index (BMI) and body surface area (BSA) of young adults at Ile-Ife with a view of determining the mean values, normal limits and sex differences in the anthropometric parameters. Four hundred and eighty four (242 males and 242 females) subjects aged between 18-41 years (inclusive) were recruited for the study. The participants were age and sex-matched (mean age: 22.81 3.83years). The weight and height of the subjects were obtained using standard techniques while BMI and BSA were calculated as derivatives of height and weight. Data were analyzed using descriptive and inferential statistics. Normal limits for height, weight and BSA were determined using 5th and 95th percentiles while normal limits for BMI were determined using 5 th and 85 th percentiles. The mean $\pm \mathrm{SD}$ and normal limits of weight, height, BMI and BSA for the 484 participants were $60.94 \pm 9.60 \mathrm{~kg}(47.00-79.75 \mathrm{~kg}), 1.67 \pm 0.85 \mathrm{~m}(1.54-1.82 \mathrm{~m}), 21.82 \pm 3.02 \mathrm{~kg} / \mathrm{m}^{2}$ $\left(17.80-24.83 \mathrm{~kg} / \mathrm{m}^{2}\right)$ and $1.68 \pm 0.15 \mathrm{~m}^{2}\left(1.45-1.96 \mathrm{~m}^{2}\right)$. Among males and females respectively, the mean weight [63.43 $\pm 9.11 \mathrm{~kg}$ and $58.46 \pm 9.46 \mathrm{~kg}(\mathrm{p}<0.001, \mathrm{t}=5.9)]$, height $\left[1.72 \pm 0.07 \mathrm{~m}\right.$ and $\left.1.62 \pm 0.07 \mathrm{~m}^{2}(\mathrm{p}<0.001, \mathrm{t}=15.03)\right]$, BMI $[21.43 \pm 2.62$ and $22.20 \pm 3.33(\mathrm{p}=0.01, \mathrm{t}=-2.83)]$ and BSA $\left[1.75 \pm 0.14 \mathrm{~m}^{2}\right.$ and $1.62 \pm 0.13 \mathrm{~m}^{2}(\mathrm{p}<0.001, \mathrm{t}=10.34]$ showed significant statistical differences. The normal limits for weight, height, BMI and BSA in males and females respectively were; $50.56-82.00 \mathrm{~kg}$ and $45.56-75.00 \mathrm{~kg} ; 1.61-1.85 \mathrm{~m}$ and $1.53-1.73 \mathrm{~m} ; 17.80-26.90$ and $17.80-28.79$ and $1.53-2.00 \mathrm{~m}^{2}$ and $1.41-1.87 \mathrm{~m}^{2}$. BMI was significantly higher in females while other anthropometric parameters were significantly higher in males. This study provides data on anthropometric parameters among young adult Nigerians as reference values for physiological and pathophysiological evaluation and clinical management. Significant sex differences exist among young adult Nigerians with regards to weight, height, BMI and BSA. So, sex should be taken into consideration in classification of young adult Nigerians using anthropometry.
\end{abstract}

Keywords: Normal Limits, Mean Values, Anthropometry, Sex Differences, Young Adults

\section{Introduction}

Anthropometry is the study of the measurement of the human body in terms of the dimensions of bone, muscle and adipose tissue. Anthropometry provides the single most portable, universally applicable, inexpensive and non-invasive technique for assessing the size, proportions and composition of the human body [1]. Anthropometric parameters reflect both health and nutritional status and predict performance, health and survival. They are very useful in public health policy development, clinical decision making, health risk assessment profiling, drug prescription, fluid requirement and disease diagnosis. Anthropometry covers a wide range of body measurements such as height, weight, body mass index, body surface area, abdominal, waist and hip circumferences, waist-hip ratio, height, length, breadth and ratios of various body parts. However, the most commonly assessed anthropometric parameters are weight, height, body mass index (BMI) or Quetelex index, body surface area (BSA) and waist/abdominal circumference. An individual can be classified based on BMI into underweight, normal weight, overweight and obese. There are evidences to suggest that anthropometric parameters vary with age, sex, ethnicity and race $[2,3]$.The ethnic and racial diversity play significant role in influencing anthropometric dimensions. The measurements of anthropometry can be used to define population groups. Even in the same nation, anthropometric database among 
different population groups such as athlete, military and students may differ. Given the level of usefulness and importance of anthropometric parameters, there is need to define normal values and normal limits for each category of population. Data is sparse with regards to reference values of anthropometry in young adult Nigerians. This study was an attempt to find out the mean values, normal limits and sex differences in the basic anthropometric parameters (weight, height, BMI and BSA) among young adult Nigerians resident in Ile-Ife, Osun State, Nigeria.

\section{Methods}

\subsection{Participants}

Four hundred and eighty four (242 males and 242 females) subjects aged between 18-41 years were recruited for the study. They were selected according to their age and sex. They were grouped into four age group categories (Table 1); 18-23 years $(69.0 \%), 24-29$ years $(24.4 \%), 30-35$ years $(4.5 \%)$ and $36-41$ years $(2.1 \%)$. The study population was drawn from people within Ilé-Ifẹ, an ancient Yoruba town in South-Western Nigeria. Only healthy volunteers (absence of systemic diseases) after initial screening process participated in the study. The screening include clinical evaluation and blood pressure assessement. Exclusion criteria include; symptomatic diseases, pedal oedema, pregnancy, athlete and arterial blood pressure $\geq 140 / 90 \mathrm{mmHg}$. The volunteers were assessed for anthropometric parameters; height and weight while their $\mathrm{BMI}$ and BSA were calculated.

\subsection{Ethical consideration}

Participation in the study was completely voluntary based on informed consent from the participants. Ethical clearance was sought and obtained from Ethics and Research Committee of Obafemi Awolowo University Teaching Hospitals Complex, Ile-Ife.

\subsection{Height and Weight Measurements}

The standing heights were measured using a stadiometer (ZT-120 Health Scale). Each participant were assessed while in good standing posture on the foot rest of the device with minimal clothing without shoes but with the head facing forward, shoulders relaxed, arms hanging loosely on both sides, palms facing forwards, feet together and knees straight. The height for each subject was taken when the movable headboard was lowered to touch the crown of the head. The measurements were taken to the nearest $0.5 \mathrm{~cm}$. The weighing scale was checked for zero balance before each use. Subjects were instructed to empty pockets and remove shoes and any apparel that could interfere with weight measurements. The subjects then stood on the scale looking straight ahead, relaxed and motionless without leaning on any object or the wall. Weight measurements were taken when the scale stabilized and recorded to the nearest $0.5 \mathrm{~kg}$ while protecting the confidentiality of subjects.

\subsection{Calculation of BMI and BSA}

BMI was calculated as weight in kilograms divided by the square of height (in metres). BMI was expressed in $\mathrm{kg} / \mathrm{m}^{2}$. The BSA was calculated using Mosteller formula [4]: $\mathrm{BSA}\left(\mathrm{m}^{2}\right)=$ (weight $(\mathrm{kg}) \times$ height $(\mathrm{cm}) / 3600)^{1 / 2}$.

\subsection{Statistical Analysis}

The data obtained during the investigation was analyzed using SPSS 16.0 for Windows P.C. The descriptive statistics were expressed as a mean \pm SD for each variable. Student t-test was carried out to detect the gender differences for each parameter: height, weight, body mass index (BMI) and body surface area (BSA). The lower and upper normal limits for height, weight and BSA were determined at 5th and 95th percentiles respectively while the lower and upper normal limits for BMI were determined at 5th and 85 th percentiles respectively [1]. A p value $<0.05$ was taken as statistically significant.

\section{Results}

\subsection{Anthropometry}

Four hundred and eight four (484) young adults participated in the study. The age range of the participant was 18-41years. The most frequent age group was 18-23years (Table 1). Among all participants $(\mathrm{N}=484)$, the mean value (normal limits) for height, weight, BMI and BSA were $1.67 \pm$ $0.09 \mathrm{~m}(1.54-1.82 \mathrm{~m}), 60.94 \pm 9.60 \mathrm{~kg}(47.00-79.75 \mathrm{~kg}), 21.82$ $\pm 3.02 \mathrm{~kg} / \mathrm{m}^{2}\left(17.80-4.83 \mathrm{~kg} / \mathrm{m}^{2}\right)$ and $1.68 \pm 0.15 \mathrm{~m}^{2}(1.45-$ $1.97 \mathrm{~m}^{2}$ ) respectively (Table 2 )

Table 1. Distribution of participants according to age group.

\begin{tabular}{lll}
\hline Age Group(years) & Male $(\mathbf{n}=\mathbf{2 4 2})$ & Female $(\mathbf{n}=\mathbf{2 4 2})$ \\
\hline $18-23$ & 167 & 167 \\
$24-29$ & 59 & 59 \\
$30-35$ & 11 & 11 \\
$36-41$ & 5 & 5 \\
\hline
\end{tabular}

Table 2. Normal limits of anthropometric measurements irrespective of gender $(N=484)$.

\begin{tabular}{llll}
\hline Variables & Minimum & Maximum & Normal Limits \\
\hline Height $(\mathrm{m})$ & 1.45 & 1.93 & $1.54-1.82$ \\
Weight $(\mathrm{kg})$ & 37.50 & 95.00 & $47.00-79.75$ \\
BMI $\left(\mathrm{kg} / \mathrm{m}^{2}\right)$ & 16.10 & 37.10 & $17.80-24.80$ \\
BSA $\left(\mathrm{m}^{2}\right)$ & 1.29 & 2.21 & $1.45-1.97$ \\
\hline
\end{tabular}

n - Number of subjects; BMI - body mass index; BSA-body surface area; Normal limits for height, weight and BSA were determined at 5th and 95th percentiles while the normal limit for BMI was determined at 5 th and 85 th percentiles.

\subsubsection{Mean Values of Anthropometric Parameters according to Sex Distribution}

The mean height, weight, BMI and BSA for male participants $(\mathrm{N}=242)$ were $1.72 \pm 0.07 \mathrm{~m}, 63.43 \pm 9.11 \mathrm{~kg}$, 
$21.43 \pm 2.63 \mathrm{~kg} / \mathrm{m}^{2}$ and $1.75 \pm 0.14 \mathrm{~m}^{2}$ respectively. The mean height, weight, BMI and BSA for the female participants $(\mathrm{N}=$ 242) were $1.62 \pm 0.07 \mathrm{~m}, 58.46 \pm 9.45 \mathrm{~kg}, 22.21 \pm 3.33 \mathrm{~kg} / \mathrm{m}^{2}$ and $1.62 \pm 0.13 \mathrm{~m}^{2}$ respectively (Table 3 ).

Table 3. Sex differences in major anthropometric parameters in age and sex-matched young adults.

\begin{tabular}{lllcl}
\hline Mean \pm SD & Male $(\mathbf{n}=\mathbf{2 4 2})$ & Female $(\mathbf{n}=\mathbf{2 4 2})$ & $\mathbf{p}$ & $\mathbf{t}$ \\
\hline Height $(\mathrm{m})$ & $1.72 \pm 0.07$ & $1.62 \pm 0.07$ & 0.001 & $15.03^{*}$ \\
Weight $(\mathrm{kg})$ & $63.43 \pm 9.11$ & $58.46 \pm 9.45$ & 0.001 & $5.89^{*}$ \\
BMI $\left(\mathrm{kg} / \mathrm{m}^{2}\right)$ & $21.43 \pm 2.63$ & $22.21 \pm 3.33$ & 0.004 & $-2.86^{*}$ \\
BSA $\left(\mathrm{m}^{2}\right)$ & $1.75 \pm 0.14$ & $1.62 \pm 0.13$ & 0.001 & $10.34^{*}$ \\
\hline
\end{tabular}

$\mathrm{n}$ - Number of subjects; BMI - body mass index; BSA-body surface area; $* \mathrm{p}<0.05$ is statistically significant

\subsubsection{Sex Differences in the Anthropometric Parameters}

The mean height $(1.72 \pm 0.07 \mathrm{~m})$ of male participants was significantly higher when compared to the mean height (1.62 $\pm 0.07 \mathrm{~m})$ of female participants $(\mathrm{p}=0.001, \mathrm{t}=15.03)$. The mean weight $(63.43 \pm 9.11 \mathrm{~kg})$ of male participants was also significantly higher than the mean weight $(58.46 \pm 9.45 \mathrm{~kg})$ of the female participants $(\mathrm{p}=0.001, \mathrm{t}=5.89)$. The mean BSA $\left(1.75 \pm 0.14 \mathrm{~m}^{2}\right)$ of male was also significantly higher than mean BSA $\left(1.62 \pm 0.13 \mathrm{~m}^{2}\right)$ of females $(\mathrm{p}=0.001, \mathrm{t}=10.34)$. However, the mean BMI $\left(22.21 \pm 3.33 \mathrm{~kg} / \mathrm{m}^{2}\right)$ of female participants was significantly higher than mean BMI $(21.43 \pm$ $\left.2.63 \mathrm{~kg} / \mathrm{m}^{2}\right)$ of males $(\mathrm{p}<0.05, \mathrm{t}=-2.86)$. The sex differences in anthropometry was illustrated in Table 3.

\subsubsection{Normal Limits of Anthropometric Parameters According to Sex Distribution}

Among male subjects $(\mathrm{n}=242)$, the normal limits for height, weight, BMI and BSA were $1.61-1.85 \mathrm{~m}, 50.58$ $82.00 \mathrm{~kg}, 17.80-23.70 \mathrm{~kg} / \mathrm{m}^{2}$ and $1.53-2.00 \mathrm{~m}^{2}$ respectively. Among female subjects $(\mathrm{n}=242)$, the normal limits for height, weight, BMI and BSA were $1.53-1.73 \mathrm{~m}, 45.58-75.00 \mathrm{~kg}$, $17.80-25.70 \mathrm{~kg} / \mathrm{m}^{2}$ and $1.41-1.87 \mathrm{~m}^{2}$ respectively (Table 4 ).

Table 4. Normal limits of anthropometric measurements in age and sex-matched young adults.

\begin{tabular}{lll}
\hline Variables & $\begin{array}{l}\text { Male }(\mathbf{n}=\mathbf{2 4 2}) \\
\text { Normal Limits }\end{array}$ & $\begin{array}{l}\text { Female }(\mathbf{n}=\mathbf{2 4 2}) \\
\text { Normal Limits }\end{array}$ \\
\hline Height $(\mathrm{m})$ & $1.61-1.85$ & $1.53-1.73$ \\
Weight $(\mathrm{kg})$ & $50.58-82.00$ & $45.58-75.00$ \\
BMI $\left(\mathrm{kg} / \mathrm{m}^{2}\right)$ & $17.80-23.70$ & $17.80-25.70$ \\
BSA $\left(\mathrm{m}^{2}\right)$ & $1.53-2.00$ & $1.41-1.87$ \\
\hline
\end{tabular}

$\mathrm{n}$ - Number of subjects; BMI - body mass index; BSA-body surface area; normal limits for height, weight and BSA were determined at 5th and 95th percentiles while the normal limit for BMI was determined at 5 th and 85 th percentiles.

\section{Discussions}

This study investigated the mean values, normal limits and gender differences of some anthropometric parameters namely; height, weight, BMI and BSA in young adult Nigerians. This was necessary in other to define anthropometric characteristics of young adult Nigerians. In clinical decision making with regards to anthropometry especially BMI, the WHO reference values [1] are usually considered the gold standard irrespective of body build of people in the nation under consideration. Moreover, in WHO reference values, sex differences seem not important. However, there are evidences to show that racial differences and sex differences exist in body build across various populations in the world. This explained while there has been growing debates with the issue of BMI cut off values for various regions of the world. The Asian-Pacific region made attempt to redefine BMI cut off value to a lower limit of 25 for their population [5-7]. In this present study, the mean height, weight and body surface area were significantly higher among males than females $(\mathrm{p}<0.001)$ whereas the BMI was significantly higher among females than males $(\mathrm{p}<$ 0.001).The result was consistent with data from previous studies with regards to the height and weight[8] but was contrary to the finding of Igiri et al, 2008 which described a higher BMI in males[8] in Calabar, a city in Southern Nigeria. A similar study in South Western Nigeria among 20-80year old by Adedoyin et al in 2008 demonstrated a pattern consistent with the outcome of this present study in terms of height, weight and body mass index but BSA was not mentioned as it was not focus of the study [9]. Most studies on anthropometry in adults exclude BSA whereas similar in infants and children may even focus on BSA[10-11]. Yet BSA is an important anthropometric parameters very useful in cancer therapy and cardiorespiratory assessment[12-14].Sex difference in body anthropometric parameters was also demonstrated among Pakistan population by Aslam et al in 2010[15].Lopez et al,2011 demonstrated sex differences among a cross-section of Spanish population[16].The sex differences were demonstrated in height, weight, waist circumference and percentage of body fat. The difference in male and female anthropometric parameters may be related to differential hormonal levels in both sexes resulting in differential body build and fat deposition [8].To date, data is sparse with regards to mean values and normal limits of height, weight, body mass index and body surface area of young adults in South-Western Nigeria. The result of this present study therefore will be useful as reference data with regards to basic anthropometry of young adult Nigerians especially among the Yoruba people of South-Western part of the country. These data can also be utilized locally for the designing of equipment for human use (commercial, industrial, or medical) and in clinical decision making especially drug prescription and usage.

Conclusion: Significant sex differences exist among young adults with regards to weight, height, BMI and BSA. So, sex should be taken into consideration in classification of young adults using anthropometry.

\section{References}

[1] WHO Expert Committee on Physical Status: The use and interpretation of anthropometry. Report of a WHO expert committee. WHO technical report series: 854 . 
[2] M.E.J. Lean, T.S. Han, H. Bush, A.S. Anderson, H. Bradby, and R. Williams, Ethnic differences in anthropometric and lifestyle measures related to coronary heart disease risk between South Asian, Italian and general population British women living in the west of Scotland. International Journal of Obesity.2001, 25pp 1800-1805.

[3] L. Yu-Cheng, J.M. Wang and E. M. Wang, The comparison of anthropometric characteristics among four peoples in East Asia Applied Ergonomics.2004; 35pp173-178.

[4] R.D. Mosteller, Simplified calculation of body surface area. New England Journal of Medicine.1987; 317(17), pp1098.

[5] W.P.T. James, C.Chen and S. Inoue, Appropriate Asian body mass indices? Obesity Review, 2002; 3 pp139.

[6] WHO expert consultation. Appropriate body-mass index for Asian populations and its implications for policy and intervention strategies. The Lancet, 2004 pp157-163.

[7] WHO/IASO/IOTF. The Asia-Pacific perspective: redefining obesity and its treatment. Health Communications Australia: Melbourne, 2000.

[8] A. Igiri, M. Ekong, C. Ogan and P. Odey. Body mass index measure of young adult Nigerians residents in the Calabar Metropolis. The Internet Journal of Biological Anthropology. $2008,2: 2$.

[9] R.A. Adedoyin, C. E. Mbada, L.A. Bisiriyu, R.A. Adebayo, M.O. Balogun and A.O. Akintomide, Relationship of anthropometric indicators with blood pressure levels and the risk of hypertension in Nigerian. Int J Gen Med. 2008, 1 pp33-40.
[10] R. El Edelbi, S. Lindemalm and S. Eksborg. Estimation of body surface area in various childhood ages-validation of the Mosteller formula. Acta Paediatr.2012,101pp 540-544.

[11] A. E. Orimolade and A.O. Omisanjo. Evaluation of five formulae for estimating body surface area of Nigerian children. Ann Med Health Sci Res.2014,4(6)pp 889-898.

[12] R.H.J. Mathijssen, F.A. DeJong, W. J.Loos, J.M. Van Der Bol, J.Verweij. Flat-fixed dosing versus body surface-based dosing of anticancer drugs in adults: Does it make a difference?. The Oncologist. 2007,12 pp 913-923.

[13] R.M. Lang, M. Bierig, R.B. Devereux, F. A. Flachskampf, E. Foster, P.A. Pellikka, M.H. Picard, M. J. Roman, J. Seward, J. Shanewise, S. Solomon, K.T. Spencer, M. J. Sutton and W. Stewart. Recommendation for chamber quantification. Eur J Echocardiography,2006,7 pp79-108

[14] J. Wanger, J.L. Clausen, A. Coates, O.F. Pedersen, V. Brusasco, F. Burgos, R. Casaburi, R. Crapo, P. Enright, C.P.M. van der Grinten, P. Gustafsson, J. Hankinson, R. Jensen, D. Johnson, N. MacIntyre, R. McKay, M.R. Miller, D. Navajas, R. Pellegrino and G. Viegi. Standardisation of the measurement of lung volumes. Eur Respir J.2005, 26 pp511-522

[15] M. Aslam, A. Saeed, G.R. Pasha and S. Altaf. Gender differences of body mass index in Adults of Pakistan: A case study of Multan City. Pakistan Journal of Nutrition.2010, 9 (2) pp162-166.

[16] P. M. Lopez, R. Fernandez-Ballesteros, M.D. Zamarron and S. R. Lopez. Anthropometric, body composition and health determinants of active ageing: A gender approach. J. Biosoc. Sci.2011,43 pp 597-610. 